curing rheumatism as it is of cancer, when nsed to alles pain in that affection; nay more, I believe that it often does harm by the excessive diaphoresis which it ocossions.

CASE N. The following case will illustrate two varieties of syphilitic rheumatism-the periosteal and muscular; and will suffice to introduce the remarks I shall have to offer in this division of the subject. My patient was a muscular well constitutioned young man, whose boast it was that he had never been obliged to lie by for a day from any illness; indeed, he seemed to be proof against all diseases but gonorrhoe. Eight years ago, after a suspicious intercourse, he had gonorrbca for the first time, with all its symptoms in a superlative degreeswelling of the penis, copious discharge, chordee, buborequiring him to keep his bed for five weeks. Two years afterwards, he agnin had gonorrhoen, but with symptoms 80 modified as to be almost uncared for; and, after consuming some three score capsules, and tanning his urethra with astringent injections, he got wcll, and so remained till within five months before the time when I first saw him. From four to five days after sexual intercourse, he percoived a purulent discharge from the urethra; but, as it was unattended by pain or other annoyance, he made himself contented about it; and it wus about this period, three weeks from the commencement, that with the yeomanry troop he went to do duty for a week prior to the annual review. He was there exposed day after day to a drenching rain; and that, coupled with the evening routine of a soldier's life, no doubt tended to the development of the rheumatism which soon followed. As soon as he settled down to his ordinary employ as a coutractor, he perceived, after walking along the uneven surface of a line of a railway, that his feet wero very tender, especially the heel, about where the plantar fascia arises. He attributed this soreness to his heavy boots, and the uncven surfaces he trod upon; but, as the tenderness increased, and progression was retarded, he consulted a surgeon, who pronounced the disease to be gonorrhueal rheumatism, and recommended him to take iodide of potassium with cinchona, and afterwards tonics with the alkaline carbonates, and an occasional alterative pill. $\mathrm{He}$ persevered with these means for some weeks; but, continuing to get worse, he determined to give up his business, and placed himself under my care.

I first saw him in July 1856. He was confined to his bed, and called my attention particularly to the state of his feet, the right one more especially; and he casually told me he had had a clap, and that there still remained a little discharge. I carefully examined the penis. There was no external swelling, no enlargement or thickening which would mark the site of an internal chancre, nor, as far as I could stretch the lips of the urethra, was there nny sore visible. Ho had not had sore. throat nor enlargement of the inguinal glands, nor any external secondary symptoms. I came to the conclusion that he had chronic urethritis, the result of a gonorrbœa, and rbeumatism of the deep fascia of the feet in connection with that disease. About two montlus from the beginning, he noticed the dis. charge was rather bloody, and remembers to have seen the recurrence of bloody discharge after using an astringent injec. tion. I gave him Plummer's pill every night, and iodide of potassium. He continued the use of the iodide, cinchona being added, till the last week in August, when, finding no im. provement, and some impatience on his part, and some anxiety on the part of his friends, I advised him to see a consulting surgeon, and, if it should be agreed upon, that he should have a change to some sea.coast. His friends overruled him, and he saw a physician, who prescribed quinine, and he went to the Isle of Man. In three weeks, he returned, much the same as when he left, but in addition he noticed that the heel-bones were larger than they should bo; he again saw the physician who had previously preseribed for him, and he was ordered to have the heels painted with iodine, and to take iodide of potassium. At length he consulted a surgeon, who judged from the history, the treatment, and the state of the feet that the disease was probably syphilitic and not gonorrhœal. $\mathrm{He}$ was brought under the influence of mercury; blisters were ap. plied alternately to the sides of the feet, and dressed with blue ointment. A mild caustic injection was used, and the iodide was given when the mercury was discontinued. He soon began to get better; tho swelling of the heels gradually diminished, the pain in the soles of the feet subsided, and he said he felt to have more spring from his feet when he tried to walk. The soles remained very tender for some time, and he had chronic rheunatic pains in his shoulders and about the back and legs. He finally cleared off these pains by recourse to, and continuance with, nitric acid and bark. This no doubt was ase of eyphilis, which I must
candidly confess I had regarded as one of gonorrhoca. The enlargement of the bones would, you might say, have been sufficient indication; but this condition showed itself only after the disease had existed for. some time, and, had it been present at the beginning, it does not neces. sarily follow that the disease must have had its origin in syphilis. This condition is not even confined to cachectic states of the system, though, true, it is usually met with in such persons; and Fuller says, "a cachectic state does not seem to be a condition essential to its development." After the subsidence of the disease in the periosteal covering, the patient had general chronic rheumatism, and this reminds me to remark that when a chronic rheumatic case is presented to $\vec{\nabla}$ us, there are two diseases which it is worth while always to dispose of by inquiry into the history, and by examination of the urine, viz., constitutional syphilis on the one haud, and granular degeneration of the kidney on the other-two very common causes of the disease.

Though iodide of potassium was given in full doses, and $\vec{\omega}$ continued over a lengthened period, there was no amendment; but directly the system was brought under mercury, the iodide became very valuable, and did very much towards facilitating is the cure. Secondary symptoms were delayed, and he had $f$ never had mercury given to salivation; but, in other cases, I .have had some remarkable instances where patients have been $\overrightarrow{0}$ salivated, and afterwards tertiary symptoms (the lepra and psoriasis particularly) and rheumatism have succumbed to the $\vec{\omega}$ iodide, only after the readministration of mercury.

When the secondary symptoms occur within six or eight $ᄋ$ weeks, the eruption is very commonly papular, and with this $\bullet$ iritis is peculiarly associated, and synovial rheumatism occa. $c$ sionally accompanies syphilitic lichen. I am inclined to regard $\subsetneq$ syphilitic iritis as rhenmatism. The iris being a muscular $\mathbb{D}$ structure, covered with a serous membrane, is as liable to $\vec{\infty}$ become affected as the synovial membranes of the joints, which, as Brodie says, very much resemble the peritoneum. The most efficacious treatment is to get the patient under mercury as speedily as possible, to keep up gentle salivation for some time, and afterwards to administer iodide of potas. sium. The joints ofter remain chronically affected, and require liniments, blisters, and other forms of local treatment. Dono-응 van's solution, the bichloride, nitric acid, and sarsaparilla may $\varrho$ also be tried in succession; indeed, in these chronic cases, it $\vec{\overrightarrow{ }}$ is advisable and advantageous to change and vary the remedies 3 repeatedly.

\section{OBSERVATIONS ON THE TREATMENT OF} ASTHMA.

By T. L. Prinhar, Esq., Surgeon, Bideford, North Devon. $\frac{3}{3}$

Mrch has been written of late on the symptoms and treatmento of asthma-perhaps the most painful and apparently alarming disease to which human flesh is heir.

The observations which I have to make on the disease are based on the experience of nearly one hundred cases whicho have come under my medical care. I may not throw much now light on the subject; yet I am desirous to record the result of my experience and my treatment, as well as myñ observations on the peculiarities of this most distressing com plaint, in the hope that some little may be added to thew stock of information which has already been collected on the subject.

It is now many years since a deep rooted impression was made on my mind, by that memorable man, Abernethy, " thate in order to treat disease, whether of a local or constitutiona character, it was absolutely necessary to keep the stomach in that state, so that the fond which was taken into it should bed properly digested, in order to secure good blood, and conse quently healthy secretions and bealthy action of the bods generally; and that in proportion as the surgeon or the phyo sician attended to these particulars, so in proportion would the means placed within the reach of the practitioner be mores or less successful".

With these impressions, which I believe to be most usefub to the medical man, I started in my profession. I had not been long in practice when a severe case of what was called humid asthma presented itself for my treatment. I found that it had been of many years standing, and frequently seemed, from its violence, to threaten the life of the patient. The attack, however, would subside after a copious expectoration 
had been thrown off from the lungs; the man at the same time becoming almost exhausted for want of nourishment, which he was not for a time able to take, except in the smallest quantities. After the lapse of a few weeks, the man would rally, eat and drink largely, and go about his work until another paroxysm threatened, when I was again in attendance. On each occa. sion of an attack, I used to say, "Ihis surely will be the last"; so severe and imminent did it appear.

This state of things went on for some time, till at last the thought occurred to me, How is it that asthmatic patients generally live to a good old age? They do not die of consump. tion; nor do the lungs undergo any other change except the dilatation of the air-cells, which dilatation of the cells does not much interfere with their normal action when free from an attack. Thus considering the matter, it appeared to me probable that the original cause of the disease was in the overworked powers of digestion; and I was borne out in this supposition by the circumstance that the patient had respite from attacks as soon as a certain amount of expectoration had been thrown off, and his stomach had for a season rested. Was it not then probable that impurities in the blood were formed by imperfect digestion, which were thrown off by means of the lungs? How far my ideas were correct, the following statement of treatment will, I think, go far to prove.

I speak now of what is called dyspeptic asthma-a disease which I believe to be peculiarly hereditary; that is to say, when the disease has once made its appearance, those who inherit it will ever be liable to attacks from imprudent diet; for I am convinced that an asthmatic person can never with impu. nity eat and drink as other people do. I may here state that, out of the number of cases which $I$ have attended, I found hereditary predisposition in nine out of ten. And if it be true that asthma is an hereditary disease, I will endeavour, by the evidence of cases which I intend to publish, to shew that wherever it has existed in any member of a family for one, two, or even three generations back, exciting causes, such as imprudent diet, an attack of bronchitis, an attack of influenza, derangement of the liver or any other functional derangement, atmospheric influences, peculiar odours, influences of the mind either for joy or sorrow, may at any time or period of life bring to light this peculiar disease, which has hitherto been latent in the system. It is fortunate that stomach-derangement from imprudent diet, etc., is, as far as my experience goes, the most frequent exciting cause-consequently more under the control of medical treatment, provided the patient has resolution enough to second the efforts of the medical attendant in carrying out a strict system of diet and regularity; in fact, it may be said that the scales are thus held with disease and suffering on one side, and comparative health and comfort on the other.

Most of the other patients inherited gout, and in some instances both diseases were traced in the family; and in more than one instance where this was apparent, I found that there were alternate attacks of asthma and gout, which is, I think, an additional evidence that both diseases are hereditary, and may be considered blood-diseases. What the peculiar element in the blood may be which produces either asthma or gout, it is to be hoped scientific researches may one day decide.

To return to my first case. The man in question, possessing some good sense, although he gave himself to beer-drinking and gross eating, as he said, to get up his strength after an attack, after having heard my views of his case, replied, "Well, sir, your remarks appear reasonable enough; and I will endeavour to follow your advice, and not eat and drink so much." I wrote down a system of dietary and general management, which for a season he followed with advantage; after this, he became tired of the plan, and again fell into intemperate habits, with an increase, if possible, of all his original fearful sufferings. He at last became reduced in circumstances, and was obliged to apply for parochial aid. I thought I had now a good opportunity of trying the effects of diet with medical treatment on this patient, and I persuaded him to go into the union house. There I took good care that he should not deviate from my prescribed treatment; for I placed him under lock and key, ordering his food to be regularly given to him, whilst he had a trustworthy attendant when he left his room for the purpose of air or exercise.

His appearance and symptoms at this time were as follows :His countenance bore the signs of great distress. His shoulders were elevated; the eyes protruded; he had no appetite; the stomach was greatly distended after eating; pulse 70 , feeble, yet regular; the tongue was coated, with fissures in it. There was great emaciation, and inability to lie down in bed or to walk up an ascent. The secretions from the bowels were dark. The urine was loaded, shewing an acid deposit.

After giving the patient an alterative pill and a saline aperient, I ordered him the following diet, which was to be regularly weighed out to him, and the hours of meals most strictly attended to. Breakfast at eight o'clock-half a pirit of green tea or coffee, with a little cream, two ounces of dry stale bread; dinner at one o'clock-two ounces of fresh beef or mutton without fat or skin, two ounces of stale dry bread or well boiled rice; three hours after dinner, half a pint of weak brandy and water, or toast-water ad libitum; supper at seven o'clock-two ounces of meat, with two ounces of dry bread. He was not allowed to drink within one hour of his dinner or supper, or till three hours after; at other times, he was not limited. Open air exercise was ordered to be taken as soon as the office of digestion had been performed, but short of fatigue. In addition to this, I ordered him three grains of the extract of conium four times a day, at the hours of seven, twelve, five, and ten; the dose to be gradually increased to five grains four times a day. Under this treatment, in a few days the whole of his distressing symptoms subsided. At the end of a month, he was allowed three ounces of meat twice a day. At the end of two months, he had gained flesh and strength, so that he was able to follow his occupation as a carpenter, which he continued to do without intermission for some years, adhering strictly to the rules laid down for him, which he had now the good sense to adopt.

My views with regard to treatment in the case were simply these: not to give the stomach more to do than it could well accomplish; not to dilute the gastric juices by fluids before or soon after eating, but to allow them to perform alone their proper functions; and to quiet the nerves of the stomach by means of a mild sedative, which prepared it for the due performance of the office of digestion. By this plan, the stomach soon began to crave for food, and a longing for the hour for taking nourishment appeared-good evidence that the powers of digestion were recovering.

Is it not reasonable, then, to suppose that a moderate quan. tity of food, well digested, supplies the system with more pure and nutritious blood than a large quantity of ill dirested food can possibly do? It appears to me not unreasonable that the poison, as it may be called, which is generated by food ill assimilated, finds its way into the circulation; and hence arises the misery of hereditary asthma, which nothing but a paroxysm, and generally a copious expectoration, will relieve. It is my intention in my next paper to give further evidence of the beneficial results of the sedative treatment of dyspeptic asthma.

[To be continuer.]

\section{ON THE EPIDEMIC SMALL-POX IN OXFORD} IN $1854-5$.

By E. L. Hussey, Surgeon to the Radeliffe Infirmary, Oxford, and Stationary Vaccinator of the National Vaccine Establishment.

BeFone the epidemic cholera appeared in Oxford in 1854 several cases of small-pox had occurred; and while the cholera was still raging, and after its ravages were at an end, small-pox spread in the city and neighbourhood more widely than on any former occasion, - at least of late years. (For notice of smallpox in 1844-5, see Mr. W. P. Ormerod, On the Sanatory Condi. tion of Oxford, 1848, p. 33.) Scarlatina, in a severe form, was also extensively prevalent at the same time, and there were many fatal cases. Fever of a low type was also prevalent, and in many cases fatal; measles and hooping.cough were also epidemic.

The late Dr. Ogle (at that time Regius Professor of Physic in the university) wished that some record should be made of the prevalence and severity of the small-pox, and of the circumstances incident to its occurrence; and he purposed to draw up a statistical report of the cases. Not being satisfied with his efforts, he gave over to me the few notes be had collected.

Numeer of CASEs. The resident medical practitioners formed a general estimate, that more than 4000 persons were attacked with the disease in different degrees of severity. The population at that time was probably more than 27,000 , and it was thought that one person in every six was attacked.

The population in August and September $185 \pm$ has been estimated at 26,474 (Memoir on the Cholera at Oxford in 1954, 